\title{
El diario Noticias: ideas económicas de la izquierda peronista durante el tercer peronismo (1973-1974)
}

\section{The Newspaper Noticias: Economic Ideas of the Peronist Left During the Third Peronism (1973-1974)}

Ignacio Andrés Rossi ${ }^{1,2, ~ * ~(D) ~ 0000-0003-3870-1630 ~}$

\footnotetext{
${ }^{1}$ Universidad Nacional de Luján, Buenos Aires, Argentina.

${ }^{2}$ Universidad Nacional de General Sarmiento, Buenos Aires, Argentina.

* Correspondencia: ignacio.a.rossi@gmail.com
}

Resumen. En el presente trabajo proponemos un examen indagatorio de las ideas económicas del diario Noticias sobre todo lo que pasa en el mundo (1973-1974), distribuido en Argentina durante los primeros años del tercer gobierno peronista (1973-1976). Para ello, analizamos las principales discusiones de la política económica nacional y mundial de aquellos años, así como las posturas sostenidas al respecto por la organización guerrillera Montoneros, a la cual se encontraba vinculado dicho diario. En la segunda parte analizamos las diatribas expresadas en Noticias en torno a diferentes aspectos de la política económica del gobierno peronista y de los principales problemas económicos de aquellos años. Se ha constatado que Noticias reproducía, en gran medida, el discurso general de Montoneros, pero se han detectado ambivalencias en el mismo que quizá muestren, tanto la naturaleza del periódico como la amplia composición ideológica de sus integrantes.

Palabras clave: Noticias; economía; política; precios; empresas.

CÓMO CITAR: Rossi, I. A. (2022). El diario Noticias: ideas económicas de la izquierda peronista durante el tercer peronismo (1973-1974). América Latina en la Historia Económica, 29(2), 1-21. DOI: 10.18232/20073496.1279 
Abstract. In this paper we propose an investigative examination of the economic ideas of the newspaper Noticias about everything that happens in the world (1973-1974) distributed in Argentina during the first years of the Third Peronist government (1973-1976). To do this, it is introduced into the main discussions of national and world economic policy of those years as well as the positions held on the subject by the Montoneros guerrilla organization to which said newspaper was linked. In a second part, we analyze the diatribes expressed in Noticias about different aspects of the economic policy of the Peronist government as well as the main economic problems of those years. It has been found that Noticias reproduced, to a large extent, the general discourse of Montoneros, but ambivalences have been detected in it that perhaps account for the nature of the newspaper and the broad composition of its members.

Key words: Noticias; economy; politics; prices; business.

JEL: N16

Recibido: 3 de diciembre de 2020.

Aceptado: 8 de julio de 2021.

Publicado: 14 de febrero de 2022.

Agradecimiento: Agradezco al Instituto del Desarrollo Económico y Social (IDEs) y a la Universidad Nacional de General Sarmiento (UNGs) por el apoyo brindado para este avance de investigación. También se agradece a los evaluadores anónimos, quienes contribuyeron con sus observaciones y sugerencias a mejorar el manuscrito.

\section{INTRODUCGIÓN}

El diario Noticias fue un periódico vinculado a la organización guerrillera Montoneros, la cual parte de un núcleo amplio de la izquierda peronista ${ }^{1}$ agrupada en los años del tercer gobierno de Juan Perón (1973-1976) en la Tendencia. ${ }^{2}$ El periódico fue parte de la iniciativa de un equipo coordinado y dirigido por el entonces militante de izquierda Miguel Bonasso, aunque una de las primeras iniciativas se le atribuye al periodista Rodolfo Walsh, quien estuvo a cargo de la sección Policiales. Como se ha mencionado, se caracterizó por reunir a un abanico amplio y heterogéneo compuesto por un staff de políticos, sindicalistas, empresarios, periodistas e intelectuales nacionales. $\mathrm{Al}$ respecto, cabe mencionar que Noticias se diferenciaba de otras publicaciones más orgánicas de Montoneros, como El Descamisado o Evita Montonera, en tanto se caracterizaba por llegar a un amplio público, así como de integrar a un conjunto complejo de colaboradores. Así, las posturas

${ }^{1}$ Con esta categoría analítica nos referimos genéricamente a las tendencias anticapitalistas y socialistas surgidas al interior del llamado peronismo, movimiento surgido desde la irrupción política del líder obrero Juan Domingo Perón (1946-1955) en Argentina entre las décadas de 1960 y 1970 (Gil, 1989). A pesar de que existen importantes controversias sobre este término frente a otros, como el de peronismo revolucionario, y teniendo en cuenta la compleja trama cultural que el peronismo significó y aún lo hace en Argentina, suponemos que la organización formaba parte de un conjunto amplio dentro de la izquierda. Para este asunto, así como para el de un estado del arte conceptual, véase Caruso, Campos, Vigo y Acha (2017).

${ }^{2}$ La Tendencia Revolucionaria, o la Tendencia, refiere al nombre que recibió en Argentina una corriente amplia del peronismo que aglutinaba a organizaciones guerrilleras como las Fuerzas Armadas Revolucionarias, Fuerzas Armadas Peronistas, Montoneros y la Juventud Peronista, quienes operaron entre las décadas de 1960 y 1970 . La organización tenía una postura combativa y revolucionaria que concebía al peronismo como un socialismo nacional y fue el baluarte de apoyo peronista durante el exilio del líder en la década de 1960 y principios de la de 1970, aunque no sin importantes pujas de poder en su interior. En aquellos años, Montoneros refería a la lucha histórica del pueblo y la nación contra el imperialismo y sus aliados, donde el peronismo constituía un aliado central para iniciar un proceso de liberación nacional mediante una lucha político-militar (Bustos, 2018). 
respecto al gobierno peronista, con quien había pujas y controversias, ${ }^{3}$ no se traducían en críticas directas o, por el contrario, en gestos explícitos de apoyo político, sino en matices y ambigüedades, como veremos.

De acuerdo a como han tratado especialmente el tema del peronismo en diversas publicaciones de historia (Panella y Korn, 2010; Rougier y Mason, 2021), sería importante tener en cuenta algunas descripciones de la fuente como objeto de estudio. Prestigiosos periodistas formaron parte del elenco de Noticias, como Horacio Verbistsky, jefe de la sección política, o los poetas Paco Urondo y Juan Gelman, jefes de redacción, aunque también colaboraron otros no vinculados políticamente a Montoneros, como Carlos Ulanovsky, Silvia Rudni, Alicia Raboy, Pablo Piacentini, Pablo Guissani, Zelmar Michelini, Sylvina Walger, Martín Caparrós y Luis Arana (Carrera y Denza, 2016). Incluso participaron otros no afiliados a un único partido y con presencia en otros medios políticos, tal es el caso del dirigente de la Unión Cívica Radical (UCR), Leopoldo Moreau, o quien fuera subdirector de la publicación en reemplazo de Urondo, Norberto Armando Habegger. La heterogeneidad daba cuenta de que el diario se había planteado como un proyecto de circulación masiva popular más que como un instrumento vocero de Montoneros.

Noticias buscaba convertirse en un diario de circulación masiva que compitiera con los grandes periódicos de la época y tomaba como modelos al diario Crónica y La Opinión, ${ }^{4}$ por lo que fue diseñado por el plástico Carlos Smoje. También contaba con importantes antecedentes de sus miembros en los diarios populares Crítica y, luego, Crónica, alcanzando un tiraje de 100000 ejemplares entre noviembre de 1973 y agosto de 1974 (Slipak, 2015). ${ }^{5}$ Su espíritu se perfilaba en grandes planas deportivas combinadas con noticias políticas, barriales y de otros intereses populares, así como en torno a la noticia internacional como epicentro del periódico. ${ }^{6} \mathrm{Al}$ respecto, siempre tuvo como referencia las luchas anticolonialistas de la época, especialmente en África y Centroamérica, en una clave popular de liberación nacional característica de aquel entonces. Por eso, se caracterizó tanto por la utilización de series de notas sobre un mismo tema en días consecutivos, en general referidas a las luchas de la izquierda en el peronismo, como por articular las noticias políticas con las de interés popular, como las deportivas, especialmente de fútbol, sin menospreciar al boxeo y el turf, mostrando así su interés por generar una alternativa periodística de alcance nacional (Slipak, 2015). Además, la estructura tradicional de los diarios comerciales a la que buscaba homologarse Noticias incluía secciones de juegos, recetas de cocina, horóscopos, cine, el Prode (pronósticos deportivos) e historietas. Respecto de esta última, cuando ingresaron Germán Oesterheld y Oscar Conti al diario, la sección adquirió una línea antiimperialista de humor gráfico (Esquivada, 2004).

Noticias tuvo una circulación diaria en formato tabloide corto con aproximadamente 24 páginas y 266 números entre el 17 de noviembre de 1973 y el 27 de agosto de 1974, con un costo de 1.50 pesos argentinos, mientras que Clarín, de un histórico alcance nacional, costaba dos pesos.

${ }^{3}$ Durante mayo de 1974 se produjo el histórico conflicto entre el líder y la organización Montoneros, cuando esta última le reclamó, en un acto del 1 de mayo en la Casa Rosada, establecido como día del trabajador, la composición del gobierno aduciendo a que estaba lleno de "gorilas", como se les acostumbraba denominar a los funcionarios, políticos y sindicalistas afiliados a las derechas. Lo más alto del conflicto se produjo cuando Perón llamó estúpidos, entre otras cosas, a los militantes y los echó de la Plaza de Mayo.

${ }^{4}$ P. Dante, P, Noticias, el diario del movimiento Montoneros, FM La UNI 97. 7. Puerta Abierta. 27 de noviembre de 2019.

${ }^{5}$ Con motivo de los seis meses de existencia del diario, se transcribía un anuncio en conmemoración y un agradecimiento al público exponiendo los nombres de los columnistas. (Noticias, núm. 172, p. 7).

${ }^{6}$ El eslogan que acompañaba a las planas era Noticias. Sobre Todo lo que Pasa en el Mundo. 
En el sistema de reparto colaboró el empresario químico Gregorio Levenson, quien organizó una sociedad anónima desde la que se buscó apoyo crediticio y se comerciaron apoyos periodísticos y publicitarios. Con un empuje financiero inicial por parte de las Fuerzas Armadas Revolucionarias (FAR) y Montoneros, el diario comenzó a tener una gran tirada, lo que le permitió realizar un acuerdo con el ministro de Economía, José Ber Gelbard (1973-1974), para conseguir una publicidad análoga al resto de los diarios, logrando finalmente una sólida autofinanciación (Esquivada, 2004). La publicación fue censurada durante el gobierno de Estela Martínez de Perón (1974-1976) (en adelante Isabel Perón), en un contexto donde, tras la muerte del líder Perón -el 1 de julio de 1974-, se desataban fuertes pujas entre la izquierda revolucionaria peronista y el gobierno peronista conservador que apoyaba la figura de Isabel Perón, sucesora a la presidencia, y José López Rega, su influyente ministro.

En este trabajo proponemos analizar específicamente las ideas económicas o que en alguna medida involucran a la política económica argentina, así como las proyecciones generales que en esta materia pueden observarse en el diario Noticias. No nos centramos tanto en constatar o cotejar las aseveraciones pronunciadas en el diario en términos empíricos, ni en ampliar los análisis existentes en este sentido, sino en indagar acerca de las concepciones de política económica que se discutían y los debates que se abrieron en torno a estas.

En este sentido, seguimos a Rougier y Odisio (2018), quienes aseguran que "detrás de los instrumentos y las condiciones sociales y económicas [desplegadas en la política económica] existen ideas que pueden considerarse el sustrato de las políticas económicas" (p. 16). Estas ideas fueron interpretadas y resignificadas por industriales, intelectuales, funcionarios, políticos, y otros actores sociales a lo largo de la historia argentina. Desde el punto de vista historiográfico, cabe destacar que el estudio de las mentalidades -ligada al ámbito francés- surgió como parte de un quiebre en los clásicos análisis de corte estructural de annales en la década de 1970 (Le Goff y Nora, 1974), aunque desde hacía una década atrás se estaban recuperando otras herramientas de análisis para conjugar diferentes temporalidades como el lenguaje, los mitos, las creencias y la iconografía (Duby, 1961). Estas fueron las primeras iniciativas de quienes se preocuparon por ampliar el examen de las estructuras materiales a las psicológicas y culturales; abandonando los esquemas más rígidos del materialismo histórico, constituyendo una apertura más aceitada al diálogo entre las ciencias sociales y proponiendo nuevos métodos de análisis. En suma, adoptamos la metodología instrumentada por los autores citados con el fin de avanzar en "una historia que no se separa del tiempo, del espacio o de la vida social, pero que tampoco las anuda mecánicamente a la estructura material" (Rougier y Odisio, 2018, p. 18). Cabe aclarar que con este examen parcializado no renunciamos a la historia total en su versión económica y social, a la que se recurre en una primera parte para introducir al lector, sino que buscamos hacer converger el examen de las ideas con la historia económica y social recuperando propuestas que hasta el momento se han encontrado separadas. Además, buscamos aportar en alguna medida a un análisis histórico-económico sobre el diario Noticias, que hasta ahora no ha recibido atención de forma específica, sino desde otras perspectivas más bien culturales, políticas y sociales.

En la primera parte analizamos las principales discusiones del contexto económico de la época en los niveles mundial, nacional y en menor medida latinoamericano. Además, presentamos un breve registro de las ideas económicas de Montoneros a partir de los principales análisis de la cuestión, así como de algunas consideraciones sobre los abordajes del diario Noticias. Luego, este artículo se divide en dos partes cronológicas en las que se analiza estrictamente el diario, pero que están conectadas por el devenir de sus ideas y propuestas económicas en los dos años que tuvo 
vida. En esta parte, la más densa del trabajo, se recuperan diferentes notas referentes a cuestiones del programa económico, como el problema de la crisis petrolera, controversias en torno a las empresas, al sector agrícola y las estrategias económicas del gobierno. Hemos tratado de poner énfasis tanto en los puntos de discusión más recurrentes como en la forma en que se argumentan las posturas político-económicas. Finalmente, buscamos recuperar algunos puntos importantes que nos permitan inferir algunas conclusiones en torno a los ejes retenidos.

\section{LA ECONOMÍA DURANTE LOS AÑOS DEL DIARIO NOTICIAS, 1973-1974, Y LA VISIÓN ECONÓMICA DE MONTONERos}

En la sección económica del periódico existió una disparidad entre los militantes vinculados directamente a Montoneros, como el economista Mario Firmenich, y el militante peronista Oscar Braun, reconocido académico proveniente de una de las familias más pudientes del país, un economista heterodoxo de reconocida trayectoria nacional e internacional quien en aquel entonces también se encontraba vinculado al peronismo revolucionario. Como este, también cabe mencionar a los economistas de Montoneros, también de renombre y formación en el exterior, Héctor Gambarotta y Carlos Bruno, quienes buscaron una articulación económica con el primero para fundar un centro de formación intelectual en el exterior, como también con otros académicos nacionales provenientes del campo económico e integrados al peronismo de izquierda como Manuel Fernández López y Carlos Morel. Aunque no contamos con evidencia empírica directa de que estos colaboraran en la sección económica (Faigón, 2014) de Noticias, es indudable su influencia en tanto se constituían como referentes económicos de la Tendencia y nutrían el discurso económico de Montoneros en aquellos años (Antúnez, 2012). Lo anterior, junto al amplio staff que participaba en sus columnas, le imprimió cierta autonomía periodística al diario respecto de los hechos abarcados y su tratamiento, al menos hasta el mencionado episodio del 1 de mayo de 1974, en cual se produjo un rompimiento entre la Tendencia y el líder del movimiento justicialista Perón (Cosse, 2018).

En este mismo sentido, los economistas que nutrían las ideas económicas de Montoneros fueron quienes replantearon, entre otras cosas, la "contradicción principal" en términos antiimperialistas, diferenciando entre los capitales europeos y estadunidenses, así como de las posibilidades de que una nación subdesarrollada como Argentina tomara ventajas de sus enfrentamientos (Pacheco, 2014). El aporte económico de estos académicos permitió que la organización se acercara desde un supuesto programa revolucionario o de socialismo nacional a una alianza peronista, en especial con la posición de la Confederación General Económica (CGE), que era afín a la burguesía industrial nacional más débil y limitada al mercado interno (Broner y Larriqueta, 1969). Especialmente, convergieron en la clasificación de Argentina como un país dependiente y oprimido por el imperialismo, que mediante este tipo de alianzas podría alcanzar una liberación nacional. Además, se identificó a enemigos en común como la oligarquía rural y los monopolios industriales, aunque también se planteaban diferencias importantes en torno al devenir del proceso socialista posterior a la liberación nacional, entendido como la construcción de un capitalismo nacional, con justicia social, independencia económica y soberanía nacional (Sanz y Lissandrello, 2018). 
La mayor parte de la actividad del diario Noticias tuvo vida durante el tercer gobierno de Juan Perón y el de Isabel Perón. A pesar de la muerte del líder, en el campo de la economía el signo fue la continuidad, mientras se mantuvo en funciones el ministro de Economía Gelbard, pero en 1975, ya siendo presidenta Isabel Perón, asumió el cargo Celestino Rodrigo y dio un vuelco la economía.

Durante la gestión de Gelbard la concertación entre la CGE, que él presidía, la Confederación General del Trabajo (CGT) y el Ministerio de Economía constituyó un plan concertado de estabilización, aunque según Gerchunoff y Llach (2020) "el centro de la discusión pública estuvo dominado por el programa de corto plazo” (p. 390). En general, podríamos decir que el programa económico de Gelbard, y en gran medida el regreso del exilio de Perón, se asentaba sobre un reformismo acorde con una alianza de clases semejante al primer peronismo (1945-1955) (Vitto, 2012). ${ }^{7}$ Respecto al capital extranjero, que ganaba espacios desde la etapa desarrollista (1958-1962), si bien la actitud de Perón al respecto era ambigua ganaba consenso en América Latina cierta reticencia impulsada por las llamadas teorías de la dependencia. Específicamente a partir de 1973 una ley sobre inversiones extranjeras buscó limitar el peso que estas venían teniendo, lo que conformó así "el primer marco legal restrictivo para la actividad de las empresas extranjeras en Argentina" (Lluch y Lanciotti, 2020, p. 186). ${ }^{8}$

A pesar de las semejanzas, una diferencia respecto al primer peronismo fue el mayor énfasis a las exportaciones industriales que, desde la década de 1960 y a partir de los debates intelectuales de la economía, ganaba consenso como mecanismo para superar los problemas recurrentes de la balanza de pagos y ganar divisas para sostener la industrialización, sin limitarse a las proveídas por el sector agrícola. Aunque en 1973 Argentina cerraba con un superávit de la balanza comercial de 1037 millones de dólares, no podía ignorarse que se trataba de un signo transitorio del alza de las materias primas y que el déficit comercial impulsado por el empuje del sector industrial no tardaría en volverse un problema. A pesar de que el orden mundial que supo establecer el sistema monetario internacional de Bretton Woods se derrumbaba desde 1971, en estos años se nacionalizó el comercio exterior con los mismos objetivos que en el peronismo de las décadas de 1940 y 1950: mantener cierto poder en los mercados internacionales. En esta línea se consumaron varios acuerdos y acercamientos comerciales con países socialistas y se discutía una ley de reforma agraria que, sin embargo, no pasó del discurso debido a su altísimo impacto político, concretándose solo una ley de impuesto a la renta potencial de la tierra. En suma, podemos aglutinar el programa del gobierno y el contexto económico en limitaciones al capital extranjero, estatización del comercio

${ }^{7}$ Existen discrepancias respecto al reformismo del programa de Gelbard. Mientras que para Vercesi (2010) o Gerchunoff y Llach (2020) son más notables las semejanzas con el primer peronismo y la tónica izquierdista es más bien discursiva, para Vitto (2012) se trató del intento de una profunda reestructuración del capitalismo argentino.

${ }^{8}$ Pueden mencionarse la Ley 20.557 que regulaba el ingreso de inversión directa, los créditos externos y los contratos que entrañaban la transferencia de valores al exterior. Por otra parte, dicha ley y el Decreto 414 dispusieron la inscripción en un registro oficial de todas las entidades que llevaran a cabo actividades en el país en representación de intereses extranjeros. Sin embargo, algunas medidas de este marco legal restrictivo para el capital extranjero resultaron ambivalentes en tanto se permitió que 49 \% de las empresas extranjeras se beneficiaran de los regímenes promocionales y el sistema de registro no terminó de instaurarse. Sin embargo, y además de introducir discusiones importantes, es indudable que en América Latina se promovían las regulaciones al capital extranjero en la crítica coyuntura mundial de 1973-1974, con los efectos de la salida de la convertibilidad del dólar y el alza de los productos primarios como shocks al paradigma de crecimiento económico y pleno empleo de corte bienestarista. Para complejizar estas cuestiones en una mirada de largo plazo, véase Lanciotti y Lluch (2018). 
exterior, términos de intercambios altos, resistencia del sector rural y centralización bancaria, pero debemos agregar que ahora había un mayor énfasis en la exportación industrial y en acabar con la inflación inmediatamente (Belini y Korol, 2020). ${ }^{9}$

El tercer peronismo insistía en diferenciarse tanto del comunismo como del capitalismo, reafirmando en política económica los pilares de la redistribución social de la riqueza, el aliento a la industrialización y la recuperación nacional de la conducción económica. Los acercamientos entre el poder político y la CGE, como parte del mismo proyecto político-económico, ${ }^{10}$ se hicieron más evidentes reafirmando la posición tercerista de los cuadros históricos del peronismo. No obstante, Rougier y Odisio (2018) señalan que las nuevas circunstancias políticas orientaban una radicalización que cuestionaba el capitalismo argentino, especialmente contra el capital extranjero y agropecuario. En suma, el proyecto de desarrollo era semejante a los planteamientos consolidados en la década de 1960, en torno a los condicionamientos del crecimiento económico y las transformaciones para el mismo. Excepto que ahora se sumaba el discurso dependentista que daba como resultado "la profundización de la sustitución de importaciones y el aliento a las exportaciones industriales [...] enmarcados por la política redistributiva” (Rougier y Odisio, 2018, p. 398) y un énfasis en la participación activa del Estado.

No obstante, el contexto internacional en este periodo resultaba poco alentador debido a la triple incidencia de la crisis petrolera que impactaba en los precios de las importaciones argentinas, las barreras proteccionistas adoptadas por la Comunidad Económica Europea y la recesión mundial a partir de 1974 con su impacto en la capacidad de compra de los mercados europeos. Sin embargo, dentro de este marco, y como signo interno del periodo histórico, Corigliano (2007) incluye la ruptura en términos de las diferencias entre los personalismos de Perón e Isabel, donde tras la muerte del primero, adquirieron un importante peso actores individuales en la política, como López Rega y el almirante Eduardo Massera, asociados a los cuadros conservadores y de derecha del peronismo. Así, la pérdida de peso de funcionarios de vital importancia en los años de Perón, como Gelbard, entre otros, se constituyó en un cuadro de ruptura respecto a los lineamientos generales de la política y la economía.

En suma, el plan del gobierno durante la segunda mitad de 1973 tuvo un impacto efectivo reduciendo las expectativas inflacionarias y la desocupación, recuperando el nivel de actividad. Sin embargo, como Belini y Korol (2020) señalaron, los éxitos iniciales subestimaron la grave crisis internacional del petróleo hacia finales de 1973, la cual, con su fuerte incremento, transmitía

${ }^{9}$ Estas medidas eran parte de las reformas estructurales que componían el Plan Trienal para la Reconstrucción y la Liberación Nacional presentado por Perón en diciembre de 1973. Se trataba de una estrategia económica diseñada por Gelbard pero que también expresaba el proyecto político del gobierno. Así, el Plan buscaba incentivar un crecimiento autónomo, la participación de la industria nacional, la apertura tanto de nuevos mercados externos como a los del Este europeo y mejorar la redistribución del ingreso. Respecto al plan de estabilización, su piedra angular era el acuerdo social descrito más arriba, semejante en su estrategia al tipo de acuerdos que Perón impulsaba desde 1952, y destinado a contener los conflictos por la distribución del ingreso, aunque presentaba algunas diferencias. Se esperaba producir ajustes salariales, paliando la fragmentación del sector obrero por encima de los precios, con el control de estos últimos mediante un congelamiento posterior por un pacto social (alianza entre trabajadores organizados en la CGT, el Estado y empresarios nacionales nucleados en la CGE) y redirigir la política financiera en favor de los sectores productivos (Belini y Korol, 2020).

${ }^{10}$ Incluso la Unión Industrial Argentina manifestó su apoyo al programa del gobierno, a pesar de constituirse en una cámara tradicional observada por la izquierda como monopolista, dadas las posiciones nacionalistas que se tornaban dominantes y que le afectaban por la naturaleza de sus actividades en el mercado interno (Rougier y Odisio, 2018). 
inflación a la economía local. ${ }^{11}$ Retomando así los conflictos laborales entre mayo y junio de 1974, y sumando al deterioro de los términos de intercambio, comenzó a enmarcarse a la economía argentina en una difícil situación para satisfacer las demandas.

En términos más generales, podemos decir que para la izquierda y la militancia juvenil peronista, la estrategia económica autónoma, de control estatal y las iniciativas de expropiación a los terratenientes eran solo un primer paso para la construcción de un socialismo nacional. Esto quiere decir que, además de proyecciones positivas en el programa de Gelbard, también se incluyeron críticas y controversias en el diario Noticias, como los beneficios otorgados a la burguesía nacional a partir de las transferencias de ingresos retenidas en el sector agropecuario, la dirección de la política crediticia al sector privado, y las endebles medidas dirigidas a los pequeños industriales frente a los grandes monopolios, entre otras. En suma, se entendía que tanto la propiedad de los medios de producción como la capacidad de reproducirlos y ampliarlos estaba en manos extranjeras. Además, se cuestionaba que estos también poseían la tecnología, la producción de bienes de capital y la capacidad financiera, comercial y administrativa para emprender los grandes negocios. De este modo, también se entendía que el gobierno pactaba con una pseudoburguesía nacional con intereses contradictorios a los del capital extranjero y la oligarquía terrateniente. Para los más radicales, la tercera posición esgrimida por el gobierno no sería más que una salida concertada con la burguesía nacional para negociar la dependencia mediante la redefinición de los vínculos con el imperialismo en términos de control estatal y proceso de acumulación (Rougier y Odisio, 2018).

En este contexto, y como dice Pacheco (2014), Montoneros entendía que el primer peronismo se había mantenido en una economía dependiente fuertemente influenciada por la oligarquía del sector agrario, aunque con un ímpetu en la industrialización liviana. La organización tampoco consideraba a la burguesía nacional como un aliado de la clase obrera, por sus características antinacionales, al margen del caso de la mencionada cGE. Así, se llegaba a la década de 1970 asegurando que el país se encontraba en una crisis económica estructural jaqueada por el imperialismo capitalista, entendiendo que no había solución posible dentro del sistema vigente. La realización de la revolución constituía la única salida para lograr un país justo y económicamente viable, donde las clases convivieran de forma conciliada (Pacheco, 2014).

Sin embargo, a partir de 1974 Argentina atravesó por un proceso de autocrítica donde redefinió su lucha por la liberación nacional. Ahora diferenciaba el imperialismo estadunidense del europeo, con cierta benevolencia en el último, y Argentina podría aprovechar ventajas de las pujas que se desarrollaban; por ejemplo en materia de inversiones. Respecto de las alianzas de clase en la economía nacional, que hasta aquel entonces solo se habían dado entre el pueblo y Perón contra el imperialismo, ahora se daba entre una mediana burguesía nacional interesada en confrontar con el imperialismo junto al pueblo contra la oposición de los monopolios estadunidenses. Así es que la contradicción fundamental se definía por la bipolaridad entre nación e imperialismo. En este marco se entendía al Estado como una pieza fundamental que, mediante la planificación económica, propiciaría la disolución del régimen capitalista para avanzar hacia un socialismo nacional que liquidara la propiedad privada (Pacheco, 2014). Aunque existían ciertas críticas a algunas acciones

${ }^{11}$ En Argentina el impacto vino por el lado del saldo comercial negativo en energía debido al alto costo de importar petróleo y sus derivados para cubrir la demanda interna. También se hizo sentir el fuerte aumento de las importaciones dado su alza a causa de la misma crisis. En 1974 el saldo comercial argentino mostraba una tendencia negativa respecto al año anterior (Barrera y Vitto, 2009). Sobre las causas de fondo de la crisis, especialmente el reposicionamiento de Estados Unidos en la hegemonía mundial y las transformaciones en términos de acumulación en el mismo, véase Harvey (2005). 
de Perón, el Estado seguía apareciendo como protector de los intereses nacionales y herramienta de transición. Sin embargo, a su vez, las definiciones y diferencias en torno al mismo y al régimen de gobierno resultaban imprecisas (Caviasca, 2006; Gillespie, 1998).

En suma, el diario Noticias se inscribió en una etapa económica bisagra, tanto en la historia económica mundial como en la nacional argentina. El keynesianismo perdía espacios en los centros de pensamiento internacional frente a las posiciones monetaristas y neoliberales que comenzaban a cuestionar el proceso de acumulación hegemónico nacido desde la posguerra. Así, los problemas de la segunda fase de la industrialización debido a la sustitución de importaciones se conjugaban con las crisis petroleras e inflacionarias mundiales que propiciaban cambios profundos en las economías nacionales, afectando a un peronismo que se aferraba a las estrategias mercado-internistas de la posguerra en un contexto hostil.

\section{DE NOVIEMBRE A MARZO: TENSIONES, CRÍTICAS Y PLANTEAMIENTOS EN TORNO AL PERONISMO Y EL SOCIALISMO NACIONAL}

En la edición de Noticias del mes de noviembre de 1973 ya se manifestaba la gran inquietud por el tema del petróleo. En un comienzo, las primeras noticias al respecto, centradas en las medidas restrictivas de uso del crudo por parte de los países europeos y de los conflictos entre Estados Unidos y el bloque soviético, ocupaban un espacio reducido (véanse Noticias, 19 de noviembre de 1973, p. 19; 21 de noviembre de 1973, p. 2 y 23 de noviembre de 1973, p. 3). En una dimensión regional, también se mostraban las preocupaciones por las tensiones generadas entre países como Bolivia y Brasil, ante la búsqueda de recursos petroleros y de gas natural y el conflicto que el distorsionado precio de las materias primas causaba (Noticias, 25 de noviembre de 1973, núm. 5, p. 3). En las siguientes ediciones ocuparon un lugar mayor el conflicto entre Israel y Egipto con las naciones árabes, así como la mediación de la Organización de las Naciones Unidas en los conflictos. Pero no sería sino en las últimas ediciones que el tema del petróleo a nivel nacional ocuparía un lugar más importante (Noticias, 26 de noviembre de 1973, núm. 6, p. 3).

En cuanto a la política económica nacional, puede notarse una inclinación favorable hacia la regulación estatal en la que, por ejemplo, se reivindicaba aún la realizada por la empresa Comercial, Industrial, Financiera del Estado Nacional ${ }^{12}$ en los frigoríficos explotados por el Estado (Noticias, 23 de noviembre de 1973, núm. 3, p. 5), a pesar de que esta había sido puesta en cuestión por los gobiernos posteriores a su creación, como el de Arturo Frondizi (1958-1962). Sin embargo, en una nota sobre una reunión entre la vicepresidente Martínez y un grupo de empresarios en torno a la formación de la Corporación de Empresas Nacionales, trascendió que el empresario Manuel Madanes, a pesar de apoyar "los objetivos de reconstrucción del gobierno nacional" (Noticias, 23 de noviembre de 1973, núm. 3, p. 5), debería enfrentar un proyecto para investigar los créditos concedidos por la banca oficial en su directorio de las empresas Fábrica de Neumáticos y Alu-

\footnotetext{
12 Esta empresa había sido creada por el primer gobierno peronista en 1949 para la realización de operaciones de financiación, comercio interior y exterior y compraventa de inmuebles. Tenía la función principal de conceder préstamos a otras empresas nucleadas en la Dirección Nacional de Industrias del Estado, un organismo que administraba empresas estatales en su mayor medida confiscadas a capitales alemanes cuando el país entró en guerra en 1945 contra Alemania y Japón, a partir de fondos del conjunto de los grupos, aunque también se proveyó de algunos monopolios comerciales, como el caso de la importación de madera de Brasil (Belini, 2007).
} 
minio Argentino, develando cierta desconfianza en sector empresarial o, quizá, más bien la puja de Montoneros al interior del movimiento la Tendencia, teniendo en cuenta los escándalos que envolvieron a esta última. ${ }^{13}$

Respecto al programa de Gelbard, a pesar de destacar sus logros iniciales durante la mayor parte de 1973 en bajar la inflación mediante el acuerdo social, las pequeñas notas al respecto evidencian cierta preocupación por "el descenso de compra del pueblo [que es explicado por] el ascenso en la cotización del dólar” (Noticias, 23 de noviembre de 1973, núm. 3, p. 6 . y 25 de noviembre de 1973, núm. 5, p. 13). A este mismo tema se le suma cierta crítica a que "las reuniones entre la CGT y la CGE se realizan al margen de las formalidades y extraoficialmente" (Noticias, 23 de noviembre de 1973, núm. 3, p. 6 y 25 de noviembre de 1973, núm. 5, p. 13) y a las discusiones entre ambas organizaciones en torno al aumento de los precios por el incremento de las importaciones, lo cual aparece como un conflicto que "tal vez solo pueda ser dirimido por el presidente de la Nación" (Noticias, 26 de noviembre de 1973, núm. 6, p. 9). Sin embargo, el conflicto que quedaba abierto frente a las argumentaciones de Gelbard, que enfatizaba en la parálisis de la inflación, era criticado por Noticias, argumentando con "estudios técnicos oficiales" (Noticias, 26 de noviembre de 1973, núm. 6, p. 9) que el costo de vida había aumentado.

Durante el mes de diciembre pueden observarse resquicios de desconfianza hacia el gobierno en el tema precios, por ejemplo, cuando se decía que "la cGT pidió a comercio que controle los costos de las empresas analizando sus libros" (Noticias, 1 de diciembre de 1973, núm. 11, p. 8), pero aun así se reflejaría el importante papel de las empresas en los acuerdos "aunque sin apelar al recurso de cortar utilidades. Si estas son disminuidas, las empresas - real o ficticiamente apremiadaspodrían optar por las suspensiones o despidos" (Noticias, 1 de diciembre de 1973, núm. 11, p. 8). Sin embargo, esto revela una actitud diferente hacia las empresas según sean de capital nacional o extranjeras o bien grandes o medianas. Por ejemplo, se explicaba la incidencia del mercado negro en el comercio mediante una denuncia de la Federación de Centros Comerciales de la Capital Federal y el Gran Buenos Aires contra empresas multinacionales. Estas cuestionaban el incentivo del desabastecimiento de materias primas contra las empresas nacionales pequeñas ${ }^{14} \mathrm{y}$ su consecuente aumento de precios (Noticias, 8 de diciembre de 1973, núm. 18, p. 8). Aunque las notas son bastante cuidadosas en sus pronunciamientos, y de hecho se encuentran basadas en comentarios y citas, en verdad no citadas sino solo de buena fe, de organismos sindicales, empresarios $\mathrm{y}$ funcionarios de gobierno, puede notarse la importancia debido a las discusiones entre tipos de empresas.

\footnotetext{
${ }^{13}$ Nos referimos al escándalo que en aquel entonces ocupó las primeras planas debido a la adjudicataria otorgada para la construcción de la planta, así como de los beneficios recibidos por el gobierno de facto de Alejandro Lanusse (19711973) por parte de los empresarios Madanes y Gelbard, con el objetivo de que estos apoyaran el Gran Acuerdo Nacional por el que el presidente buscaba ganar consensos entre los actores políticos y económicos. Los casos de corrupción fueron desempolvados por el partido opositor de la UCR y ampliamente cubiertos por la prensa (Blejmar, 2019).

${ }^{14}$ El tema del mercado negro fue denunciado como una medida estratégica de las empresas por limitar la oferta al no poder aumentar los precios y no por falta de insumos o materias primas (Noticias, 8 de enero de 1974, núm. 47, p. 8).
} 
El tema del desabastecimiento aparece a su vez como una oportunidad para denunciar la lucha entre pequeños productores y monopolios. ${ }^{15}$ Por ejemplo, en una nota que recrea un conflicto entre tamberos y el gobierno, se anuncia un posible desabastecimiento de los penúltimos de no aceptarse un aumento del precio; ${ }^{16}$ estos "defenderían sus reclamos 'aun con medidas que no deseamos tomar' [reproduciendo a los tamberos], expresión que aparentemente encierra la amenaza de no entregar el producto al mercado” (Noticias, 15 de febrero de 1974, núm. 84, p. 4). Este tipo de especulaciones reproducidas le servían a Noticias para recrear la lucha entre monopolios y pequeños productores y revindicar las virtudes de estos últimos, donde el aumento del precio no solo era un problema de los industriales de la leche, sino también de los pequeños tamberos, que de no fijarse un precio "único y uniforme quedaban a la merced de la actividad monopólica de los 'industriales lecheros' [y que estos últimos] se conformaban con un precio que cubriera los gastos de producción a fin de favorecer a las cooperativas y no incrementar los precios en las bocas de expendio" (Noticias, 15 de febrero de 1974, núm. 84, p. 4).

En una nota dedicada al problema de la producción agraria se denunciaba que "los productores no producen porque dicen que se les fija los precios. Pero cuando se les suben los precios tampoco producen" (Noticias, 13 de febrero de 1974, núm. 82, p. 11), asegurando que: "Se trata de un fenómeno muy conocido, que en la jerga de los economistas suele disfrazarse con la idea de "escasa o nula elasticidad de oferta del campo' [tratándose de] leyes que todavía aparecen en el pizarrón de las facultades pero que, si alguna vez respondieron a la verdad, hace mucho que dejaron de hacerlo" (Noticias, 13 de febrero de 1974, núm. 82, p. 11).

De esta forma, se criticaba al campo argentino, del que "se dice que está en paralizado porque le falta mecanización. Pero resulta que hoy, cuando en la Argentina hay 180 mil tractores, se siembra prácticamente lo mismo que cuando no había ninguno" (Noticias, 13 de febrero de 1974, núm. 82, p. 11). Incluso en otra nota se diría que: "El nivel productivo siguió estancado y el gobierno popular tuvo que intervenir la CAP [Corporación Argentina de Productores de Carne] al descubrir que los patrióticos ganaderos estaban subfacturando exportaciones, para quedarse con una apetitosa diferencia de plata negra en el exterior" (Noticias, 14 de febrero de 1974, núm. 83, p. 11).

El tema no era considerado menor, ni solo blanco de críticas al capital agrario, sino que "es decisivo, pues la 'elasticidad de la oferta agropecuaria' representa uno de los cuellos de botella [en referencia a las crisis del balance de pagos] que impiden a la economía argentina mantener un ritmo sostenido de crecimiento" (Noticias, 14 de febrero de 1974, núm. 83, p. 11). Asimismo, destaca la crítica al gobierno y su estrategia de concertación para incentivar el crecimiento del campo:

${ }^{15}$ Este constituía un problema de larga data en Argentina y remitía a los problemas generados en los mercados cuando la intervención estatal en materia de precios o de protección específica provocaba especulaciones con las mercaderías. Desde el primer peronismo (1945-1955) pueden registrarse problemas de desabastecimiento relacionados a los controles gubernamentales, incluso antes también aparecen problemas de desabastecimiento en mercados locales. En los años analizados, incluso los sectores económicos aliados al gobierno, identificados como una pequeña burguesía nacional, recurrían a este tipo de prácticas denominadas como de mercado negro ante la disminución de sus beneficios frente a los congelamientos de precios. Especialmente en un escenario de fuertes aumentos de los insumos importados del exterior, estos empresarios experimentaban importantes pérdidas de rentabilidad (Vitto, 2012).

16 También, en la misma línea, el problema del desabastecimiento en el mercado de los cigarrillos puede verse como una maniobra oligopólica para aumentar el precio del producto haciendo desaparecer a las marcas menores y lanzando una oferta de cigarrillos caros como Benson, perjudicando su vez a los consumidores y quioscos (Noticias, 8 de marzo de 1974, núm. 104, p. 4 y 9 de marzo de 1974, núm. 105, p. 4). 
“la 'concertación’ ya se ha intentado varias veces [...] el resultado fue el que vimos: se premió al campo con una formidable transferencia de ingresos y la producción quedó igual” (Noticias, 13 de febrero de 1974, núm. 82. p. 11).

Respecto al tema del mercado negro puede notarse la preocupación de Noticias por el contrabando, ampliamente señalado en algunas notas. Por ejemplo, se reproducía una conferencia de Gelbard sobre el contrabando de pollos y jamones a países limítrofes, pero también de naftas, donde el ministro señalaba que esto, en parte, era producto de los bajos precios en Argentina donde "ocupamos el cuarto lugar en el mundo en el menor costo de vida" (Noticias, 24 de enero de 1974, núm. 62, p. 10). La noticia señalaba con cierto contraste que "se había decidido formar una comisión especial para coordinar la represión al contrabando” (Noticias, 24 de enero de 1974, núm. 62, p. 10), aunque "al mismo tiempo, se anunciaba en la Secretaría de Comercio la Decisión de autorizar un aumento del orden del 10 por ciento en el precio de los pollos al consumidor [y se citaba] 'en virtud de las modificaciones sufridas en la estructura de costos de producción del sector avícola'" (Noticias, 24 de enero de 1974, núm. 62, p. 10).

Por otro lado, durante el mismo mes destacan algunos cuestionamientos al tema de la deuda que Argentina adquirió en el exterior. Por ejemplo, en un anuncio de Gelbard al anunciar préstamos del Banco Interamericano de Desarrollo (BID) por 756 millones de dólares se señalaría que "sin embargo, el crédito del BID no podrá servir para financiar las ventas a Cuba: solo beneficia a exportaciones de países miembros de la entidad crediticia" (Noticias, 18 de diciembre de 1973, núm. 28, p. 10). Más abajo, Noticias no tardaría en advertir que, "si los préstamos anunciados se concretasen, el país habría duplicado la masa crediticia obtenida en la institución desde 1961" (Noticias, 18 de diciembre de 1973, núm. 28, p. 10). Desde un punto de vista similar en otra nota se reproducían los pronunciamientos de Julio Broner, entonces presidente de la CGE, al decir que debemos "dejar de lado interesadas ayudas externas" y que una economía de abundancia "puede lograrse con nuestro propio capital y capacidad de ahorro" (Noticias, 2 de diciembre de 1973, núm. 12, p. 10), revelando cierta reticencia con las instituciones financieras internacionales.

Quizá en este mismo sentido puede analizase la nota en la que Noticias le dedica casi media plana al empresario nacional de EMEPA, César Cao Saravia, en el marco de un convenio para exportar vagones y material ferroviario a Cuba. ${ }^{17}$ Especialmente se destaca de este empresario, además de reproducir sus mismos dichos sobre el servicio que daba a la patria, la importancia de su origen sobre "los duros comienzos de su infancia misérrima" en Salta y cómo se convirtió desde abajo en un empresario nacional contrario al imperialismo (Noticias, 11 de enero de 1974, núm. 50, p. 8). Pero en la larga nota, además de contar la historia del empresario, se trasladaría el punto al comercio con Cuba, donde Noticias cuestionaba: “ ¿No se han dado, acaso, todas las facilidades para realizarla? [y el empresario contestaría] No -sostiene él-. Se publicita la facilidad, pero se oculta la dificultad" (Noticias, 11 de enero de 1974, núm. 50, p. 8). También, y en relación con el BID, el diario interroga: “¿Usará EMEPA los créditos del BID para la operación? Cao Saravia se indigna: el BID, el Banco Mundial, el Fondo Monetario solo son organismos creados para detener el avance de los pueblos" (Noticias, 11 de enero de 1974, núm. 50, p. 8). Así, Noticias acopla sus proyeccio-

${ }^{17}$ En noticias posteriores a la concreción de los acuerdos comerciales con la isla, Noticias denunciaba que, "la 'prensa' ignoró la misión argentina a Cuba. 'Clarín' defiende las inversiones norteamericanas” y luego de revisar la importancia que le dedicara la prensa en general a los acuerdos comerciales entre ambos países, aseguraba que “Noticias fue el único matutino de ayer que consideró razonablemente otorgar al diálogo de Gelbard con Fidel Castro su título principal de tapa" (Noticias, 28 de febrero de 1974, núm. 96, p. 8). 
nes sobre el comercio con un país socialista y su representación de un empresario acorde con el proyecto nacional y popular que se profesaba, un empresario que de su empresa "no se considera su dueño, sino su responsable" (Noticias, 11 de enero de 1974, núm. 50, p. 8). ${ }^{18}$

Durante el mismo mes, el lanzamiento de Plan Trienal también ocupó gran parte de las planas y las noticias producidas señalaban ciertas tensiones. Por ejemplo, un periodista del diario interrogó a Adelino Romero, entonces secretario de la CGT, "Si bien se estima que el salario real no ha sufrido una caída, los trabajadores quieren un reajuste de salarios para mejorar su situación ¿La CGT está de acuerdo con ese pedido?”, y Romero contestó: “yo diría que usted lo está diciendo, no la clase trabajadora” (Noticias, 28 de diciembre de 1973, núm. 37, p. 8). Luego, en una tirada posterior, también sobre el Plan Trienal, se reproducían las palabras de Gelbard al decir que "lo que acabamos de hacer no fue un juego intelectual destinado a buscar un envase más bonito para enquistar la dependencia, sino una denotada investigación de los medios que nos permitirían liberarnos cuanto antes de los nefastos poderes del colonialismo económico, ideológico y cultural" (Noticias, 29 de diciembre de 1973, núm. 38, pp. 12 y 13), aunque como contraste se advertía: "dijo Gelbard que un moderado bienestar para todos es mejor que la loca sociedad de consumo" (Noticias, 29 de diciembre de 1973, núm. 38, pp. 12 y 13). Esto, luego de citar cómo el ministro justificaba la imposibilidad de que el sector trabajador aumentara su participación en el producto y que dijera que: "no serán expropiadas las bocas de expendio de empresas privadas" petroleras en una situación tan difícil como la que se encontraba Argentina en el tema petrolero (Noticias, 29 de diciembre de 1973, núm. 38, pp. 12 y 13). De una forma similar, y respecto a este último tema, se anunciaba en otra nota que la Federación Obrera Tucumana de la Industria del Azúcar pedía al Ministerio de Economía estatizar la Compañía Nacional Azucarera, argumentando que "sus directivos fueron detenidos por encubrimiento de partidas de azúcar" (Noticias, 6 de enero de 1974, núm. 45, p. 8).

A pesar de ciertas críticas y rispideces, Noticias reafirmaba el apoyo general al gobierno del pueblo, con el que de todas formas se mantenían cuestionamientos ambivalentes. Así lo hacía notar en una plana completa encabezada por la leyenda "El gobierno del pueblo defiende su nivel de vida [...] el gobierno del pueblo defiende su salario [y] el gobierno del pueblo hizo fuerte su aguinaldo" (Noticias, 14 de enero de 1974, núm. 52. p. 7), además de que se presentaban estadísticas y gráficos defendiendo con indicadores las premisas citadas. Esta campaña publicitaria en sintonía con el gobierno alcanzó a la publicidad de Noticias donde, en planas enteras, se compartían anuncios de la Secretaría de Prensa y Difusión de la Presidencia Nacional. Por ejemplo, en una de ellas, destinada a restringir el uso de combustibles ante la situación internacional, se decía:

No lea este anuncio con su coche en marcha [...] usted, de esta manera, ahorrara combustible. No consumir combustible superfluo es una de las formas para economizar petróleo. Esto es lo que el país necesita, ahora, para su reconstrucción. La clave para consumir menos petróleo es no derrochar energía y combustible, mediante una

${ }^{18}$ Más adelante, cuando ocurrió el primer embarque de productos argentinos a Cuba, Noticias recreaba el hecho como parte de un conflicto entre el gobierno estadunidense y la iniciativa empresarial-gubernamental argentina. Especialmente se decía que Henry Kissinger, secretario de Estado estadunidense, manifestaba que aún se encontraba en estudio la venta de automóviles por parte de compañías estadunidenses a Cuba radicadas en Argentina, pero Noticias aprovechó para traslucir las palabras de Gelbard: "La Argentina es soberana y lo seguirá siendo. Ese es un problema de Kissinger. En la Argentina decidimos nosotros” (Noticias, 26 de febrero de 1974, núm. 94, p. 10). 
utilización mesurada y racional. Cuide el país, cuidándose. La reconstrucción bien entendida empieza por casa: no malgaste combustible (Noticias, 16 de enero de 1974, núm. 54, p. 7). ${ }^{19}$

De cada 10 litros que usted carga, uno viene de afuera. No lo use. El gobierno se ha impuesto un periodo de prueba: el mes de febrero. Si usted no coopera, se deberán tomar medidas que no se correspondan con un pueblo maduro. No lo use (Noticias, 6 de febrero de 1974 , núm. 75 , p. 7).

En esta misma línea de apoyo al gobierno, frente a un pueblo maduro, se decía en una nota sobre un proyecto de exploración petrolera de Yacimientos Petrolíferos Fiscales (YPF) que "constituye un respaldo a los objetivos de reconstrucción nacional del gobierno del General Perón" (Noticias, 6 de febrero de 1974, núm. 75, p. 11). ${ }^{20}$ Aunque también el tema, en los últimos números de Noticias, fuera tratado a nivel nacional con expectativas en que el gobierno emprendía una reforma hidrocarburífera que constituía un "paso importante en el camino de la independencia económica [tendente a] la nacionalización de la explotación petrolera [y la] revisión de los contratos vigentes con las empresas privadas. [Y se afirma que] su aprobación sería una de las definiciones económicas y políticas más importantes del actual gobierno" (Noticias, 25 de julio de 1974, núm. 237, p. 12). ${ }^{21}$

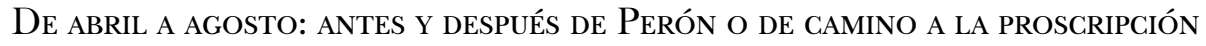

Durante esta segunda etapa, las preocupaciones de Noticias en torno a los problemas políticoeconómicos y la coyuntura económica en general no tuvieron grandes cambios. Sin embargo, son dignas de analizar para tener un panorama completo de los meses en que el periódico tuvo vida y conectar algunos puntos de examen. Las cuestiones que involucraban a los precios, y en general al programa del gobierno, siguieron teniendo algunas posiciones ambivalentes. En el mes de abril se transcribía una nota del Ministerio de Economía atribuida a Perón, asegurando que el reajuste de los precios en el marco del Acta de Compromiso Nacional ${ }^{22}$ se orientaba a que "las nuevas tarifas se harán con sentido social, [procurando] que el pueblo controle los precios y que los empresarios sigan colaborando con sentido social" (Noticias, 1 de abril de 1974, núm. 128, p. 3), o que "el

${ }^{19}$ También un anuncio de estas características en Noticias (18 de enero de 1974, núm. 56, p. 7) y en favor de la recaudación impositiva o "blanqueo" en Noticias (16 de enero de 1974, núm. 54, p. 9, y 24 de enero de 1974, núm. 62 , p. 10).

${ }^{20}$ Es recurrente en la estrategia comunicativa del diario citar a sindicalistas o funcionarios de gobierno mediante sus expresiones políticas. Muchos de ellos finalizan con referencias de este tipo, que los autores en este caso específico adjudicaban vagamente al sindicalismo, pero que parece más bien una estrategia en tanto la conexión con la línea argumentativa de las notas periodísticas que exceden a dicha nota es evidente.

${ }^{21}$ Más adelante, este tema generaría controversias entre quienes defendían el monopolio completo de la exploración, extracción, industrialización y comercialización de todos los hidrocarburos, aún al destacar la posibilidad de que el monopolio estatal no se llevara a cabo agresivamente, pero cuestionando las posturas que, como Gómez Morales, aseguraban que "sería un inconveniente nacionalizar las empresas extranjeras del ramo por las dificultades económicas que sufre el país” (Noticias, 11 de agosto de 1974, núm. 253, p. 1).

${ }^{22}$ Se trató de un documento firmado el 30 de mayo de 1973 por la CGT, la CGE y el ministro Gelbard para acordar líneas programáticas tales como una redistribución progresiva del ingreso, aumentar la actividad económica, controlar la inflación, la fuga de capitales y avanzar en materia impositiva, el control de cambios y la restricción de la importación de bienes de lujo competitivos con la industria nacional (Rapoport, 2020). 
Gobierno del Pueblo aumentó las tarifas [refiere a transportes], PERO [sic] cuidó que el reajuste afecte menos a los usuarios que menos ganan" (Noticias, 14 de abril de 1974, núm. 143, p. 14). La cuestión de los precios comenzaba a hacerse presente en varias notas y generaría tensiones, aunque todavía se referenciaban las declaraciones de Gelbard al asegurar que "no aumentará el costo de vida" (Noticias, 29 de abril de 1974, núm. 155, p. 7). Este argumentaba que tales alzas se hacían primero calculando la incidencia de los precios en los salarios. Sin embargo, y con cierta reticencia, se decía que "el aumento del precio del pan y la leche es una de las alzas que más inciden en el costo de vida, puesto que esos productos se toman como indicadores debido a su consumo masivo" (Noticias, 25 de abril de 1974, núm. 151, p. 6).

Por otra parte, también era recurrente la cuestión del comercio con el bloque socialista, en este caso con el Este europeo, donde, en el marco de una misión entre empresarios y el ministro Gelbard, se aseguraba que: "el ministro y el grupo de funcionarios que integran su comitiva, suscribirán diversos acuerdos comerciales [con la] intención de establecer nuevos contactos con representantes de las empresas estatales de dichos países socialistas" (Noticias, 25 de abril de 1974, núm. 151, p. 6). Así, se dedicaba un amplio espacio a los acuerdos sectoriales con Rusia, Polonia, Checoslovaquia y Hungría, tendentes a generar "acuerdos de complementación económica y tecnológica, incluyendo la formación de empresas mixtas” (Noticias, 23 de abril de 1974, núm. 149, p. 12). ${ }^{23}$ De hecho, se llegó a afirmar que estos acuerdos se tornaron importantes para Argentina en tanto "tenemos asegurado el desarrollo energético en todas sus fases a través de los acuerdos logrados" (Noticias, 14 de mayo de 1974, núm. 170, p. 10), y se agregaba que "el país sabe [...] que puede moverse con total libertad en este campo y encarar todos los proyectos de envergadura sin tener que pasar por el tamiz del Fondo Monetario Internacional y el Banco Mundial, fuentes de crédito que nos han obligado tradicionalmente a una actitud mendicante, a la compra de equipos de baja calidad y a condiciones financieras onerosas" (Noticias, 14 de mayo de 1974, núm. 170, p. 10), y que "la apertura a los países socialistas es el camino más sensato" (Noticias, 6 de junio de 1974, núm. 192, p. 10). ${ }^{24}$

Por otro lado, la cuestión de las empresas y el desabastecimiento siguió generando diatribas contra los monopolios. Por ejemplo, se denunciaba la falta de estireno y su impacto en la industria del plástico ante una merma de la producción que "afectó a los elaboradores de sachets, envases de plástico, juguetes [etcétera]" (Noticias, 2 de abril de 1974, núm. 129, p. 9), apuntando directamente a "la única fabricante de estireno en nuestro país": Petroquímica Argentina S. A., empresa integrada por varias compañías estadunidenses, empresa que "cuadruplicó la producción [...] redujo el personal” (Noticias, 2 de abril de 1974, núm. 129, p. 9). Además, esta provocó demoras de la producción e interrupciones que impactaron en "la falta de materia prima" (Noticias, 2 de abril

${ }^{23}$ En unos números posteriores, y ya avanzados dichos acuerdos, se reproducía mediante un gráfico los productos que los países del Este comprarían a Argentina (Noticias, 6 de junio de 1974, núm. 192, p. 7).

${ }^{24}$ En cuanto a esta última afirmación se advertía que la mayoría de los mercados de colocación de productos argentinos se estaba concentrando en Estados Unidos y Europa Occidental. Y que el déficit con Estados Unidos, se decía, "sumaba más de 1500 millones de dólares", mientras que, por el contrario, se destacaban los créditos ofrecidos por países socialistas a Argentina a abonarse en mercaderías y la disposición de empresas mixtas en contratar mano de obra local (Noticias, 6 de junio de 1974, núm. 192, pp. 10 y 11). 
de 1974, núm. 129, p. 9). ${ }^{25}$ En otra nota posterior se dejaba ver que la denuncia del desabastecimiento se encontraba imbuida por una fuerte idea de distribución, y se aseguraba que "una sociedad avanzada no puede ser guiada exclusivamente por el criterio de 'economicidad'. La idea de justicia debe campear en la distribución [...] como prueba concreta de la eficacia del orden social en su conjunto" (Noticias, 5 de junio de 1974, núm. 191, p. 11). En esta línea, y aunque se denunciaría que son "los monopolios, nacionales ${ }^{26}$ o extranjeros [que] con su posición de poder" no respetaban los criterios, se dijo que para transformar la realidad "hacen falta dos condiciones: proyectos claros y participación total" (Noticias, 24 de agosto de 1964, núm. 263, p. 5). ${ }^{27}$

No obstante, respecto a temas hasta aquí mencionados, que en gran medida no son tan novedosos en comparación a los revelados en los primeros meses de Noticias, destaca con más firmeza la cuestión de la intervención del gobierno en áreas específicas. Por ejemplo en aquella que tendrá que ver directamente con el sector televisivo, con una portada completa y una declaración firmada por la Juventud Trabajadora Peronista, en la cual se apoyaba "al gobierno nacional en su decisión de estatizar completamente la televisión de nuestro país, impidiendo que se vuelta a entregar a manos privadas nacionales o extranjeras" (Noticias, 3 de junio de 1974, núm. 189, p. 7). Cabe mencionar que aparece de forma más constante una denuncia al imperialismo y al aparato del Estado, el cual "orienta todos sus mecanismos para impedir la proliferación de reivindicaciones obreras [en aras de generar] un clima de estabilidad y tranquilidad [...] para restablecer la confianza” (Noticias, 15 de junio de 1974, núm. 199, p. 12). Ahora se exigía acción real en contra de los monopolios especuladores y los grandes oligarcas. Puntualmente que se apoyara a la movilización amplia de los trabajadores con la participación activa de los pequeños y medianos empresarios, como única garantía de fuerza real para detener las maniobras de los agentes del imperialismo (Noticias, 15 de junio de 1974, núm. 199, p. 12).

También aparecía con cierta fuerza el tema de la propiedad de la tierra, donde luego de asegurar que el agro es una variable estratégica para la política económica del país, se sostuvo que "el monto y costos de esa producción están sujetos a modos de tendencias y explotación de la tierra, anacrónicos, decadentes" (Noticias, 15 de junio de 1974, núm. 199, p. 12) y que en los últimos años el sector había sido responsable del aumento generalizado de precios. Esto se relaciona con que "se está en presencia del comienzo de un nuevo ciclo ganadero" (Noticias, 15 de junio de 1974, núm. 199, p. 12) donde, dada la mayor demanda internacional de productos agrícolas y la capacidad del sector para trasladar sus actividades, se producía un aumento de precios internos. Así, afirmaban que "el nudo de la cuestión consiste en que mientras se mantenga vigente la apropiación

${ }^{25}$ El empresario Cao Saravia nuevamente aparece denunciando en Noticias que "la mayor dificultad en estos momentos reside en el desabastecimiento de materias primas". Por consiguiente, se recrean sus palabras diciendo, "lo que ha provocado el actual desabastecimiento de materias primas fue el énfasis exagerado en la estabilidad, [cuando el problema] no consiste en la estabilidad sino en la distribución de la riqueza" (Noticias, 3 de abril de 1974, núm. 130, p. 11).

${ }^{26}$ Por ejemplo, la misma denuncia se arremetía contra el sector agropecuario, especialmente el mercado de carnes del cual se entendía que, ante las disconformidades por los acuerdos de precios y aumentos menores de lo exigido por el sector, se producían desabastecimientos (Noticias, 24 de agosto de 1964, núm. 263, p. 5).

${ }^{27}$ En un número posterior, se dijo más fulgurantemente que "solo el pueblo movilizado permitirá al gobierno castigar a los monopolios culpables con la expulsión", refiriéndose en verdad a los oligarcas que "han decidido conformar una central que los agrupe, Confederación General Agraria [y] los monopolios” (Noticias, 15 de junio de 1974, núm. 199, p. 12). 
monopólica de un recurso insustituible e irreproducible como es la tierra; mientras la propiedad privada sobre estos medios de producción siga manteniéndose incólume, será muy poco probable evitar las consecuencias" (Noticias, 15 de junio de 1974, núm. 199, p. 12).

Ya fallecido Perón, en julio de 1974, Noticias mostraba ciertas inquietudes que parecían radicalizar sus ideas. Por ejemplo, se señalaba que la inflación pasaba a ser entendida por una ofensiva liberal de la oligarquía. Al respecto se decía que "el otorgamiento del aguinaldo sirvió para que se agitara nuevamente el fantasma de la inflación [donde] el fuerte impulso al consumo determinado por los nuevos ingresos terminaría volviéndose en contra de los trabajadores como consecuencia de los [...] aumentos de precios" (Noticias, 14 de julio de 1974, núm. 226, p. 6). El diario argumentaba que el aguinaldo se dirigiría a consumos transitorios, haciendo difícil que "se vuelque hacia otras formas de gasto más duraderas o hacia el ahorro" (Noticias, 14 de julio de 1974, núm. 226, p. 6), por ende invalidando el carácter inflacionario que se le atribuía. También se decía que las causas de la inflación radicaban en la no inversión de las grandes empresas y en los aumentos de precios concedidos por el gobierno. Por esto, y un poco contradictoriamente, se decía que "si los empresarios no aceptan aumentar la producción, la nueva masa monetaria originada en el medio aguinaldo empujará los precios hacia arriba" (Noticias, 14 de julio de 1974, núm. 226, p. 6). ${ }^{28}$

$\mathrm{Al}$ respecto del sector agropecuario, se señalaban las “facilidades impositivas" (Noticias, $27 \mathrm{de}$ julio de 1974, núm. 239, p. 12) que introducía el gobierno en el marco de las restricciones impuestas por el Mercado Común Europeo, como la prolongación de impuestos y futuras evaluaciones en la reducción de los mismos. Mientras tanto, en la misma nota y como contrapartida de las medidas menos expansivas, se señalaba que la CGE solicitaba "al presidente del Banco Central, Alfredo Gómez Morales, que adopte una política más flexible en materia de créditos evitando la adopción de criterios excesivamente monetaristas" (Noticias, 27 de julio de 1974, núm. 239, p. 12). Cuando al siguiente mes las rebajas impositivas fueran instrumentadas por el gobierno, se advertiría que "el Estado dejará de percibir alrededor de 50 mil millones de pesos moneda nacional; es decir, un tercio de la suma inicialmente prevista que era de 150 mil millones" (Noticias, 10 de agosto de 1974, núm. 252, p. 11). En suma, la mirada de Noticias en cuanto al sector agropecuario se componía de un conjunto de actores: los grandes agropecuarios organizados en la Sociedad Rural Argentina (SRA) y la Confederación Rural Argentina (CRA), que pujaban por beneficios como aumentos de precios y desgravación impositiva. También, el Ministerio de Economía, que se aferraba a la Comisión de Política Concertada, aseguraba que "no significa conceder todo lo que se le pida al gobierno" (Noticias, 19 de junio de 1974, núm. 203, p. 10) y por último, las ligas agrarias, sectores de pequeños productores que "denuncian a sectores del agro que lo único que les interesa es mantener sus privilegios y trabar toda su acción positiva del gobierno como, por ejemplo, el proyecto de Ley Agraria” (Noticias, 19 de junio de 1974, núm. 203, p. 10).

La cuestión de la Comunidad Económica Europea fue presentada a menudo como contrapartida a los empresarios nacionales organizados en la CGE. Estos, aseguraban mediante su titular Broner que al "colonialismo agroimportador [le afecta que] la Argentina haya adoptado una política exterior que permite comerciar con 3500 millones de habitantes [mientras que] esos mismos sectores no han podido negociar por su cuenta los 600 millones de dólares que le hemos vendido a Cuba” (Noticias, 25 de agosto de 1974, núm. 264, p. 8). En este sentido, también se ubica al Pacto

${ }^{28}$ Esta preocupación fue manifestada en notas posteriores en donde se trataba el problema de la emisión monetaria y las restricciones que el titular del Banco Central imponía. Por ejemplo, véase Noticias (31 de julio de 1974, núm. 243, p. 12). 
Social, promovido por el gobierno como "el garante del crecimiento del salario real", y por eso salvaguarda del asalariado mientras se asegura también que "se debe combatir el desabastecimiento" contra quienes se oponen al desarrollo del país (Noticias, 25 de agosto de 1974, núm. 264, p. 8).

Si bien no puede decirse que las críticas al gobierno eran directas, luego de la muerte de Perón comenzaba a preocupar en cierta medida el devenir del proyecto económico y social. Por un lado se rescataban los pronunciamientos de Gelbard quien, luego de exponer los avances económicos en materia de crecimiento, inversiones y salarios, decía que "a medida que avanzamos [...] arrecia la acción de los que lucraban con la dependencia y el estancamiento nacional" (Noticias, 24 de agosto de 1974, núm. 263, p. 9); por otro lado, y quizá con cierta preocupación, se señalaba otro pronunciamiento de Gelbard al decir que "el pueblo pasa de la resignación de pretensiones justas a demandas que exceden las posibilidades reales del sistema económico" y quien, a su vez, recurría a Perón para rememorar su ideal de modelo nacional, asegurando que "Argentina debe convertirse en una Potencia Intermedia, con una alta participación popular en su vida política y económica" (Noticias, 24 de agosto de 1974, núm. 263, p. 9).

\section{Conclusiones}

Hemos podido observar cómo el diario Noticias construyó ideas económicas de una forma indirecta, si tenemos en cuenta que estas no ocupan la mayor parte de las planas y que se encuentran entremezcladas con temáticas más generales del contexto político del país. No obstante, mediante algunas ideas que hemos retenido, y que recorren los meses en que el mismo tuvo sus tiradas hasta antes de ser intervenido, podemos arrojar algunos puntos de análisis. La cuestión de las empresas fue una de las que más espacio ocupó en los debates, donde se ha podido constatar que, a pesar de que por momentos se reivindicaba a la empresa nacional, no se trataba de cualquier tipo de nacionalismo empresarial, por el contrario, se trataba de un perfil específico de empresario antiimperialista y predispuesto a las relaciones con bloques socialistas del globo, de las cuales se señalaban sus amplios beneficios en comparación con el mundo occidental. El panorama cambia cuando la discusión abordaba a las empresas pequeñas, las cuales son presentadas en la mayoría de los casos como víctimas afectadas por los grandes monopolios culpables de los aumentos de precios y el desabastecimiento de materias primas y otros productos. Por otra parte, la preocupación por el poder de compra del pueblo trabajador estuvo siempre a la orden del día, pero paulatinamente fue mostrando una resignación desde la capacidad de Perón para dirimir los conflictos -asunto agravado con su muerte-, hasta las manifestaciones de un avance liberal que percibía en ese precio el principal problema inflacionario. Al respecto, se esgrimieron argumentos propios a modo de causas de la inflación, aunque, por otra parte, se reconocía el empuje salarial como un problema.

En este sentido, también puede inscribirse la cuestión del tecnicismo económico, aspecto que se le critica al gobierno y a algún miembro de su equipo económico, aunque, por otra parte, se recurriera a gráficos y datos duros para analizar la evolución de la productividad del campo y formular críticas al sector. Esto también resulta llamativo, dada la naturaleza del diario de corte popular destinado a sectores trabajadores, y por eso con un amplio espacio para el deporte y otras cuestiones de interés masivo. El sector agrario es quizá el más vapuleado en las diatribas de Noticias, y con el que menos ambigüedad en ese sentido se le trata, en tanto es percibido como una oligarquía ineficaz por su tendencia a comerciar con el bloque occidental -relaciones que se encontraban en 
crisis en aquel entonces-, su baja disponibilidad a invertir y aumentar la producción, así como de su predisposición a aprovechar los beneficios del gobierno como la desgravación impositiva y la concesión de determinados aumentos en precios específicos como las carnes.

A pesar de ello, pudo observarse un por momentos inusitados el apoyo al gobierno popular en materia de ahorro energético, de administración impositiva, de justificación oficial en torno al cuidado de la política salarial hacia los menos favorecidos, entre otras cosas. Las planas completas reproduciendo anuncios de las diferentes secretarías del gobierno y el apoyo manifestado al mismo contrastan, en cierta medida, con las críticas que se infiltraban un poco indirectamente al llamado gobierno popular. Por ejemplo, a pesar de reproducir los discursos antiimperialistas de Gelbard o el presidente de la GGE, no dejaba de exhibirse la pérdida del poder de compra del pueblo, de señalar el énfasis en la estabilidad y el control monetario, y de plantear la posibilidad de avanzar en expropiaciones y estatizaciones. Tras la muerte de Perón aparecía la idea de que el pueblo organizado puede frenar problemas como el desabastecimiento, la reticencia inversora y el monopolio de los sectores económicos, mientras que los proyectos de estatización se mezclaban con las posibilidades de expropiaciones reproducidas en algunos actores a los que se les daba voz mediante citas. Sin embargo, en este sentido, la postura del gobierno resultó bastante vaga al presentarse la cuestión de la estabilidad y la confianza nuevamente en un contexto mundial hostil.

\section{LISTA DE REFERENCIAS}

Antúnez, D. (2012). La tendencia revolucionaria del peronismo y los gobernadores populares. Boletín de Posgrado En Historia, 1, 1-17.

Barrera, M. y Vitto, C. (2009). El plan energético del tercer gobierno peronista (1973-1976): Potencialidades, limitaciones y consecuencias de la crisis del petróleo. Presentado en III Jornadas de Economía Política, Buenos Aires, Argentina.

Belini, C. (2007). Una experiencia fallida de empresa pública industrial: La Dirección Nacional de Industrias del Estado, 1949-1962. En J. Schvarzer, T. Gómez y M. Rougier (eds.), La empresa ayer y hoy: Nuevas investigaciones y debates (pp. 93-135). Buenos Aires: Universidad de Buenos Aires.

Belini, C. y Korol, J. (2020). Historia económica de la Argentina: En los siglos XX y XXI. Buenos Aires: Siglo Veintiuno.

Blejmar, J. (2019). José Ber Gelbard: La patria desde el boliche. Buenos Aires: Universidad Nacional de General Sarmiento.

Broner, J. y Larriqueta, D. (1969). La revolución industrial argentina. Buenos Aires: Sudamericana.

Bustos, M. (2018). Montoneros: La vía armada sobre la democrática: Los conceptos de Resistencia y Liberación en la revista Evita Montonera (1974-1979). Temas de Historia Argentina y Americana, 26(2), 32-77.

Carrera, P. y Denza, N. (2016). Prensa para la revolución: Comunicación política y de masas en el PRTERP y Montoneros. Argentina: Tren en Movimiento.

Caruso, V., Campos, E., Vigo, M. y Acha, O. (2017). Izquierda peronista: Una categoría útil para el análisis histórico. Historiografías, 14, 68-90. Dor: 10.26754/ojs_historiografias/hrht. 2017142337

Caviasca, G. (2006). Dos caminos: ERP-Montoneros en los setenta. Buenos Aires: Centro Cultural de la Cooperación Floreal Gorini. 
Corigliano, F. (2007). Colapso estatal y política exterior: El caso de la Argentina (des)gobernada por Isabel Perón (1974-1976). Revista SAAP: Sociedad Argentina de Análisis Político, 3(1), 5579.

Cosse, I. (2018). "Pibes" en el centro de la escena: Infancia, sensibilidades y lucha política en la Argentina de los setenta. En S. Favero, E. de Moura y S. Sosenski (eds.), Infâncias na história do Brasil e da América Latina (século xx) (pp. 232-257). Ponta Grossa: Todo Palavra.

Duby, G. (1961). Histories des mentalités. En C. Samaran (ed.), L'Histoire et ses méthodes (pp. 937966). París: Gallimard.

Esquivada, G. (2004). El diario Noticias: Los Montoneros en la prensa argentina. La Plata: Universidad Nacional de La Plata.

Faigón, M. (2014). La montonerización de la izquierda juvenil peronista (1972-1973): El caso de la revista Envido. PolHis, 7(13), 134-151.

Gerchunoff, P. y Llach, L. (2020). El ciclo de la ilusión y el desencanto: Políticas económicas argentinas de 1880 a nuestros días. Buenos Aires: Crítica.

Gil, G. (1989). La izquierda peronista: Transitando los bordes de la revolución (1955-1974). Buenos Aires: CEAL.

Gillespie, R. (1998). Los soldados de Perón: Los Montoneros. Buenos Aires: Grijalbo.

Harvey, D. (2005). El nuevo desafío imperial: Acumulación por desposesión. Buenos Aires: CLACSO.

Lanciotti, N. y Lluch, A. (2018). Las empresas extranjeras en la Argentina: Del siglo XIX al siglo XXI. Buenos Aires: Imago Mundi.

Le Goff, J. y Nora, P. (1974). Faire de l'histoire. París: Gallimard.

Lluch, A. y Lanciotti, N. (2020). Estado y empresarios en Argentina: Política y economía, 19552001. En C. Belini y O. Barsky (eds.), Estado y empresarios en Argentina: Política y economía, 1955-2001 (pp. 171-211). Buenos Aires: Lenguaje Claro.

Noticias sobre Todo lo que Pasa en el Mundo (1973-1974). Buenos Aires, Argentina.

Pacheco, J. (2014). Montoneros a la luz de su programa. Revista THEOMAI. Estudios Criticos sobre Sociedad y Desarrollo, 21, 1-21.

Panella, C. y Korn, G. (2010). Ideas y debates para la nueva Argentina: Revistas culturales y políticas del peronismo (1946-1955). Buenos Aires: Ediciones de Periodismo y Comunicación.

Rapoport, M. (2020). Historia social, económica y política de la Argentina (1880-2003). Buenos Aires: Crítica.

Rougier, M. y Mason, C. (2021). Las palabras se las lleva el viento, lo escrito queda. Revistas y economía durante el primer peronismo (1945-1955). Buenos Aires: EUDEBA.

Rougier, M. y Odisio, J. (2018). "Argentina será industrial o no cumplirá sus destinos": Las ideas sobre el desarrollo nacional (1914-1980). Buenos Aires: Imago Mundi.

Sanz, G. y Lissandrello, G. (2018). El programa de liberación nacional en la Argentina de los '70: La convergencia entre Montoneros y la Confederación General Económica (CGE). Conflicto Social, 11(19), 100-132.

Slipak, D. (2015). Las revistas montoneras: Cómo la organización construyó su identidad a través de sus publicaciones. Buenos Aires: Siglo Veintiuno.

Vercesi, A. (2010). Política Económica Argentina 1973-1976. Influencias Doctrinarias. VI Jornadas de Sociología de la UNLP. Presentado en La Plata. La Plata: Universidad Nacional de La Plata. Facultad de Humanidades y Ciencias de la Educación. Recuperado de https://www.aacade mica.org/000-027/140 
Vitto, C. (2012). Plan económico del tercer gobierno peronista. Gestión de Gelbard (1973-1974). Problemas del Desarrollo. Revista Latinoamericana de Economía, 43(171), 111-134. DoI: 10.222 01/iiec.20078951e.2012.171.33585

Vitto, C. (2013). La política económica del tercer gobierno peronista y las principales rupturas entre las gestiones de Gelbard y Rodrigo. Cadernos PROLAM/USP, 12(22), 9-21. Dor: 10.11606/issn.1676-6288.prolam.2013.82513 